ORIGINAL ARTICLE

\title{
Dampened ventilatory response to added dead space in newborns of smoking mothers
}

\author{
R Y Bhat, S Broughton, B Khetriwal, G F Rafferty, S Hannam, A D Milner, A Greenough
}

Arch Dis Child Fetal Neonatal Ed 2005;90:F316-F319. doi: 10.1136/adc.2004.061457

See end of article for authors' affiliations .....................

Correspondence to: Professor Greenough, Department of Child Health, King's College Hospital, Denmark Hill, London SE5 9PJ UK; anne.greenough@ kcl.ac.uk

Accepted

30 December 2004

Published Online First 5 May 2005
1 fants whose mothers smoke during pregnancy are at increased risk of sudden infant death syndrome compared with infants of non-smoking mothers; the increase in risk has been reported to be twofold to fourfold, but as high as sixfold if associated with other risk factors. ${ }^{1-3}$ A possible explanation for the association is that the infants have neurodevelopmental abnormalities of the control of ventilation. ${ }^{4}$ If that explanation were correct, infants of smoking mothers would be predicted to have a reduced ventilatory response to hypercarbia. ${ }^{4-6}$ Term newborns can compensate fully for an imposed dead space (tube breathing) by increasing their minute ventilation. ${ }^{7}$ It has been argued that hypercarbia is the most important stimulus to ventilation during tube breathing. ${ }^{89}$ If then infants of smoking mothers do have neurodevelopmental abnormalities of ventilation, they would be predicted to have an impaired ventilatory response to tube breathing. The aim of this study was to test that hypothesis. We therefore compared the response to tube breathing of infants of smoking and non-smoking mothers, all examined in the first week after birth before discharge from hospital.

\section{METHODS}

Infants of smoking and non-smoking mothers were recruited from the postnatal wards. Smoking status was determined by questioning the mothers and examining their antenatal records. Smoking mothers admitted smoking at least five cigarettes a day throughout pregnancy. Cigarette smoking was recorded to the nearest five cigarettes a day. Urinary cotinine concentrations were not assessed. Infants were recruited if born at term, more than 6 hours old, and had no obstetric or perinatal problems. Informed, written parental consent was obtained, and the study approved by the King's College Hospital Ethics Committee.

Infants were studied while awake, but quiet. Their eyes were open, and the infants were breathing quietly when the measurements were made. A face mask was placed over the infant's nose and mouth. A $7 \mathrm{~mm}$ tube led from the face mask to a pneumotachograph (PK Morgan, Rainham, Kent, UK) via a Y connector. The length of the tube between face mask and Y connector was adjusted such that its volume was $4.4 \mathrm{ml} / \mathrm{kg}$ body weight, twice the anatomical dead space. The pneumotachograph was attached to a differential pressure transducer (MP45; Validyne Corporation, Northridge, California, USA), the signal from which was recorded on a chart recorder (RS3600; Gould, Bilthoven, the Netherlands). Flow, measured from the pneumotachograph, was electronically integrated to give tidal volume and recorded on the chart recorder. From the tidal volume and the duration of inspiratory and expiratory cycle (which were used to calculate respiratory rate), the breath to breath minute volume (MV) was calculated. A second $7 \mathrm{~mm}$ tube connected the face mask to a three way tap through which a bias flow of 2 litres/min was delivered to the circuit. A third tube connected the three way tap to the remaining part of the Y connector (fig 1).

Baseline recordings of MV were made with the three way tap in the neutral position, so that the bias flow to the face mask eliminated any dead space. When the tap was rotated, the bias flow was fed via the third tube directly to the Y connector and the pneumotachograph so that the bias flow now bypassed the face mask. This resulted in the dead space of the second tube being added to the infant's respiratory system. The infant breathed through the additional dead space until the breath by breath MV no longer increased, and the maximum minute ventilation (MMV) had been reached. The breath by breath MV was plotted against time. A polynomial regression line was drawn through the data points collected from when the infant started to breath through the additional dead space. The MMV and the time

Abbreviations: $M M V$, maximum minute ventilation; $M V$, minute volume 


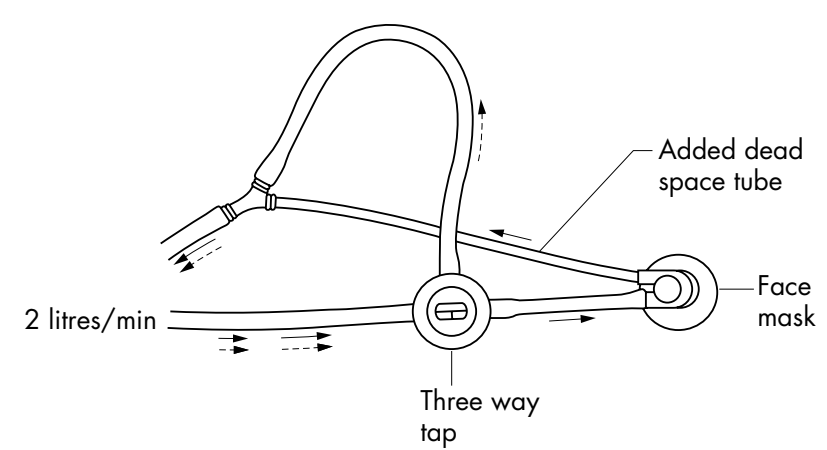

Figure 1 Apparatus used to measure the response to added dead space. When the three way tap is turned to be in the vertical position, this diverts the bias flow from the face mask, and the infant has to breathe from the added dead space tube as indicated.

constant Tc (the time taken to achieve $63 \%$ ) of the increase in MV were then calculated. ${ }^{10}$ In four infants, the study was repeated 15 minutes later; the coefficient of repeatability of Tc was 11 seconds.

\section{Statistical analysis}

Differences between the groups were assessed for statistical analysis using the Mann-Whitney $\mathrm{U}$, the paired Wilcoxon, or $\chi^{2}$ test as appropriate. Logistic regression analysis was then performed to determine whether the smoking status of the mother predicted the Tc independently of birth weight, gestational age, postnatal age, and sex. Analysis was performed using SPSS version 12.0 (SPSS Inc, Chicago, Illinois, USA).

\section{Sample size}

Recruitment of 14 infants into each group allowed, with at least $80 \%$ power at the $5 \%$ level, detection of a difference in the Tc greater than six seconds, about $50 \%$ of the coefficient of repeatability of the measurement. In a previous study, ${ }^{10}$ the mean Tc in term infants was 27-29.6 seconds, thus our sample size allowed us to detect a difference between the two groups of $25 \%$ or less of the Tc expected in term infants. ${ }^{10}$ Recruitment continued until 14 infants were recruited into the smoking group.

\section{RESULTS}

Thirty eight infants, including 14 of smoking mothers, were recruited. The median number of cigarettes per day smoked by the mother was five (range 5-15). The infants of the smoking and the non-smoking mothers were similar with regard to their sex distribution, birth weight, and gestational and postnatal age (table 1 ).

There were no significant differences between the baseline or "dead space added" tidal volumes, respiratory rates, or inspiratory or expiratory times of the two groups. In both groups, addition of the dead space caused significant increases in tidal volume and respiratory rate (table 2).

The baseline MV, the MMV, and the change in MV expressed as a percentage of the baseline MV did not differ significantly between the two groups. The median Tc of the infants of the smoking mothers was significantly greater than that of the infants of non-smoking mothers $(p=0.016)$ (fig 2; table 3). Regression analysis showed that the smoking status of the mother was significantly related to the Tc adjusted for birth weight, gestational and postnatal age, and $\operatorname{sex}(p=0.018)$.

\section{DISCUSSION}

We have shown that infants of smoking mothers had a dampened ventilatory response to added dead space-that is, the time constant of the response was longer. The infants of smoking mothers tended, although not significantly, to be older than the infants of non-smoking mothers. Maturation and a greater response to tube breathing has been shown in the first 10 days after birth. ${ }^{10}$ Thus the poorer response of infants of smoking mothers is even more striking. Results of mouth pressure measurements 100 milliseconds after an airway occlusion at the onset of inspiration $\left(\mathrm{P}_{0.1}\right)$ also suggested that infants of smoking mothers had a reduced ventilatory drive and there was a dose-response relation with the number of cigarettes smoked. ${ }^{11}$ A confident conclusion on the strength of respiratory drive of infants of smoking mothers, however, cannot be made on the basis of $\mathrm{P}_{0.1}$ measurement results, as the magnitude of $\mathrm{P}_{0.1}$ not only reflects respiratory drive, but also respiratory muscle strength.

Although the Tc differed significantly between the two groups, the MMV and change in MV during tube breathing were similar. It is possible that, as we based our sample size calculation on the Tc results, we may have had insufficient power to confidently detect differences in the other variables. Our results, however, showing a significant difference in Tc, but similar changes in MMV in the two groups are predictable from the results obtained in healthy infants. ${ }^{7}$ Healthy infants of more than 36 weeks of gestational age have been shown to be able to fully compensate with regard to their MV for two additional dead spaces. ${ }^{7}$ Hence, we predicted that the infants of smoking and non-smoking mothers would compensate for the added dead space with similar changes in MV, but the Tc of their response would differ and hence based our sample size calculation on Tc data.

The mechanisms by which babies increase their MV to compensate for added dead space are by increasing their tidal volume and their respiratory rate. In both groups in response to the added space, their tidal volume and respiratory rate significantly increased (table 2 ). In both groups, the increase in respiratory rate resulted from a significant reduction in expiratory time, but in the infants of non-smoking mothers there was also a shortening of the inspiratory time. The latter effect, although significant, however, was a mean difference of only 0.04 second.

\begin{tabular}{llll} 
Table 1 & Comparison of infants of smoking and non-smoking mothers & \\
\hline & $\begin{array}{l}\text { Infants of smoking } \\
\text { mothers }\end{array}$ & $\begin{array}{l}\text { Infants of non-smoking } \\
\text { mothers }\end{array}$ & p Value \\
\hline Number & 14 & 24 & \\
Male & 7 & 15 & 1.00 \\
SVD & 10 & 16 & 0.24 \\
Gestational age (weeks) & $39(37-42)$ & $40(38-42)$ & 0.98 \\
Birth weight (g) & $3440(2740-4100)$ & $3400(2780-4300)$ & 0.28 \\
Postnatal age (hours) & $37(11-85)$ & $26(10-120)$ & \\
\hline Where applicable, data are median (range). & & \\
SVD, Spontaneous vaginal delivery. & & \\
\hline
\end{tabular}


Table 2 Tidal volumes, respiratory rates, and inspiratory and expiratory times before (baseline) and with the added dead space

\begin{tabular}{llll}
\hline & Baseline & Added dead space & p Value \\
\hline $\begin{array}{l}\text { Non-smoking mothers } \\
\text { Tidal volume }(\mathrm{ml} / \mathrm{kg})\end{array}$ & $3.6(2-6)$ & $5.4(4-8.8)$ & \\
Respiratory rate $($ breaths $/ \mathrm{min})$ & $42(28-71)$ & $49(27-74)$ & 0.0001 \\
Ti (seconds) & $0.6(0.4-1.1)$ & $0.6(0.4-1.1)$ & 0.0001 \\
Te (seconds) & $0.8(0.4-1.4)$ & $0.7(0.4-1.2)$ & 0.02 \\
Smoking mothers & & & \\
Tidal volume $(\mathrm{ml} / \mathrm{kg})$ & $3.8(2.6-7)$ & $6(3.2-12)$ & 0.0004 \\
Respiratory rate $($ breaths/min) & $34(27-59)$ & $43(25-67)$ & 0.02 \\
Ti (seconds) & $0.6(0.4-1)$ & $0.6(0.4-0.8)$ & 0.53 \\
Te (seconds) & $1.1(0.6-1.5)$ & $0.8(0.6-1)$ & 0.055 \\
\hline
\end{tabular}

Data are median (range).

Ti, Inspiratory time; Te, expiratory time.

$\begin{aligned} & \text { Table } 3 \text { Comparison of response to the added dead space of infants of smoking and } \\
& \text { non-smoking mothers }\end{aligned}$
\begin{tabular}{llll}
\hline & $\begin{array}{l}\text { Infants of smoking } \\
\text { mothers }\end{array}$ & $\begin{array}{l}\text { Infants of non-smoking } \\
\text { mothers }\end{array}$ & p Value \\
\hline Baseline $\mathrm{MV}(\mathrm{ml} / \mathrm{min} / \mathrm{kg})$ & $150(119-275)$ & $164(80-263)$ & 0.71 \\
$\mathrm{MMV}(\mathrm{ml} / \mathrm{min} / \mathrm{kg})$ & $400(262-631)$ & $349(192-518)$ & 0.26 \\
Change in $\mathrm{MV}(\%)$ & $120.8(84.3-216.7)$ & $164.3(80-263)$ & 0.09 \\
Tc of the response (seconds) & $37.3(22.2-70.2)$ & $26.2(13.8-41.9)$ & 0.016 \\
\hline
\end{tabular}

Data are median (range)

MMV, Maximum minute ventilation; MV, minute volume; Tc, time constant.

The Tc-that is, to achieve $63 \%$ MMV during tube breathing - has been noted to be faster in active compared with quiet sleep when infants were examined in the first 10 days after birth. ${ }^{8}$ Thus, although the ventilatory responses preceding hypoxia induced arousal have not been shown to differ between sleep states, ${ }^{12}$ we took care to always test the infants when they were awake, but quiet, and so avoid a possible confounding effect of sleep state. We assessed the infants using behavioural criteria only, but when they were measured they were breathing regularly and had their eyes open, so we do feel they were awake rather than in active, rapid eye movement sleep. Previous studies examining ventilatory control have usually examined infants when asleep, this difference needs to be remembered when interpreting our results in the context of the literature. We assessed maternal smoking status by questioning the mothers and examining their antenatal records. Urinary cotinine concentrations were not assessed, nor did we have data on the mother's exposure to smoking by others in her workplace. Infant hair urinary cotinine measurements in an early study, ${ }^{13}$ however, did not show overlap between a maternally declared exposure group and a control group, and

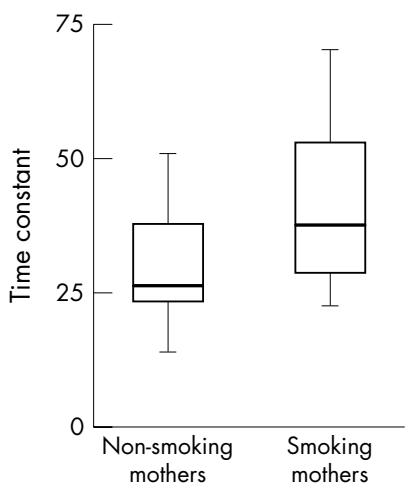

a good correlation $\left(r^{2}=0.63\right)$ was found with maternal reports of smoking. Despite a lack of cotinine measurements in our study, we did find a significant difference in the response to the added dead space between infants whose mothers we classified as smokers and those as non-smokers.

Potentially, the apparatus resistance, hypoxia, and hypercarbia could have stimulated the infants' ventilation during tube breathing. ${ }^{8}$ Experiments in which the dead space was ventilated by a fan showed, however, that only $28 \%$ of the increase in MV was due to the resistive effect of the added dead space tubing. ${ }^{8}$ In addition, measurements in air and $30 \%$ oxygen using a similar technique to that used in our study yielded similar results, ${ }^{8}$ suggesting that hypoxia is not a major stimulus. Thus hypercarbia would appear to be the most important stimulus to ventilation during tube breathing. Indeed, the addition of two added dead spaces has been shown to increase the end tidal $\mathrm{CO}_{2}$ by only $1.8 \mathrm{~mm} \mathrm{Hg} .{ }^{9}$ Thus, our data suggest that infants of smoking mothers might have a dampened ventilatory response to hypercarbia. The implications of this are that, in adverse conditions, affected infants may develop carbon dioxide retention and associated adverse consequences.

Studies examining the ventilatory response to hypercarbia in infants of smoking mothers have yielded conflicting results. ${ }^{4-6}$ Some have shown an increased response, ${ }^{56}$ whereas in a third study ${ }^{4}$ no significant difference was noted between infants of smoking and non-smoking mothers. ${ }^{4}$ In the first two studies, ${ }^{5}{ }^{6}$ however, the response to a combined hypercapnic/hypoxic stimulus was examined, but in the third $^{4}$ the hypoxic and hypercapnic stimuli were administered separately. In that study, ${ }^{4}$ however, the infants of the smoking mothers were significantly older than the control infants and this may have influenced the results. Both groups ${ }^{4}$ were examined between 2 and 3 months of age, whereas we assessed babies in the first week after birth, which may account for the differences in the results of the two studies. Previous studies ${ }^{4-6}$ have examined infants outside the neonatal period and thus the results could have 


\section{What is already known on this topic}

Infants whose mothers smoke during pregnancy are at a sixfold increased risk for sudden infant death syndrome. It is possible that this is due to neurodevelopmental abnormalities of the control of ventilation.

\section{What this study adds}

We have shown that, in the perinatal period, infants of smoking mothers have a dampened ventilatory response to an imposed dead space. This result is compatible with dampened chemoreceptor function following in utero exposure to cigarette smoking.

been influenced by postnatal, as well as antenatal, smoking exposure. We therefore deliberately chose to examine infants in the first week after birth and importantly before hospital discharge. Thus the infants were likely to have only been exposed to antenatal smoking, thereby allowing us to examine whether antenatal smoke exposure alone influenced ventilatory control.

Prenatal nicotine exposure results in cell death in the brainstem of animal models. ${ }^{14}$ The abnormalities may result from fetal hypoxia, as nicotine is a powerful vasoconstrictor and reduces blood flow to the uterus, as well as having a direct vasoconstrictor effect on the fetus. ${ }^{15}$ In addition, fetuses of smoking mothers have raised carboxyhaemoglobin concentrations, resulting in a decrease in fetal oxygen tension, a shift in the oxygen dissociation curve to the left, and a decrease in oxygen delivery to the tissues. ${ }^{16-18}$ Nicotine is also a specific neuroteratogen; exposure to nicotine during critical phases of central nervous system development has resulted in abnormalities of cell replication, cell differentiation, and receptor function in rat fetuses. ${ }^{19-21}$ Prolonged exposure to nicotine at low doses throughout gestation has led to altered brain development, corresponding to the appearance of nicotinic receptors in the midbrain ${ }^{22}$ and reductions in noradrenaline (norepinephrine) concentrations in the cerebral cortex, midbrain, and hippocampus. ${ }^{21}$ In human fetuses, high concentrations of nicotine binding sites in brainstem tegmental nuclei related to cardiopulmonary integration during mid-gestation may make those areas more susceptible to nicotine toxicity during critical periods of brain development. ${ }^{23}$ Both peripheral and central chemoreceptor function in lambs have been shown to be altered by nicotine. ${ }^{24}$ Such abnormalities may explain our finding of a dampened response to tube breathing in the infants of smoking mothers.

In conclusion, infants of smoking mothers had a dampened response to tube breathing compared with infants of non-smoking mothers. The major provoking stimulus to ventilation during tube breathing in the neonate is hypercarbia. Our results are compatible with dampened chemoreceptor function in infants exposed in utero to cigarette smoking. It is possible that this is a manifestation of neurodevelopmental abnormalities of the control of ventilation, which have been suggested to be a cause of the association of the increased rate of sudden infant death syndrome in infants of smoking mothers. ${ }^{4}$ Longitudinal studies are required to further test this hypothesis.

\section{ACKNOWLEDGEMENTS}

RB was supported by the Joint Research Committee, King's College Hospital, and BK and SB by King's College Hospital Trust. We thank Mrs Ashley Cain and Mrs Deirdre Gibbons for secretarial assistance.

\section{Authors' affiliations}

R Y Bhat, S Broughton, B Khetriwal, G F Rafferty, S Hannam, A D Milner, A Greenough, Division of Asthma, Allergy and Lung Biology, Guy's, King's and St Thomas' School of Medicine, King's College London, UK

\section{Competing interests: none declared}

This study was approved by the King's College Hospital Ethics Committee.

\section{REFERENCES}

1 Mitchell EA, Tuohy PG, Brunt JM, et al. Risk factors for sudden infant death syndrome following the prevention campaign in New Zealand. Pediatrics 1997; 100:835-40.

2 Williams SM, Mitchell EA, Taylor BJ. Are risk factors for sudden infant death syndrome different at night? Arch Dis Child 2002;87:274-8.

3 Chong DS, Yip PS, Karlberg J. Maternal smoking: an increasing unique risk factor for sudden infant death syndrome. Acta Pediatr 2004;93:450-2.

4 Lewis KW, Bosque EM. Deficient hypoxia awakening response in infants of smoking mothers: possible relationship to sudden infant death syndrome. J Pediatr 1995; 127:6919-33.

5 Galland BC, Taylor BJ, Bolton DPG, et al. Respiratory responses to hypoxia/ hypercapnia in small for gestational age infants influenced by maternal smoking. Arch Dis Child Fetal Neonatal Ed 2003;88:F217-22.

6 Campbell AJ, Galland BC, Bolton DPG, et al. Ventilatory responses to rebreathing in infants exposed to maternal smoking. Acta Paediatr 2001;90:793-800.

7 Upton CJ, Milner AD, Stokes GM. Response to tube breathing in preterm infants with apnoea. Pediatr Pulmonol 1992;12:23-8.

8 Upton CJ, Milner AD, Stokes GM, et al. What are the mechanisms producing increased ventilation in dead space studies in neonates. Pediatr Pulmonol 1990;9:136-9.

9 Stokes GM, Milner AD, Wilson AJ, et al. Ventilatory response to increased dead spaces in the first week of life. Pediatr Pulmonol 1986;2:89-93.

10 Upton CJ, Milner AD, Stokes GM, et al. Dynamic response to tube breathing during the first 10 days of life. Paediatr Pulmonol 1990;9:72-9.

11 Ueda Y, Stick SM, Hall G, et al. Control of breathing in infants born to smoking mothers. J Pediatr 1999;135:226-32.

12 Parslow PM, Harding R, Cranage SM, et al. Ventilatory responses preceding hypoxia-induced arousal in infants: effect of sleep state. Respir Physiol Neurobiol 2003;136:235-47.

13 Spvik S, Lossus K, Wallo L. Heart rate response to transient chemoreceptor stimulation in term infants is modified by exposure to maternal smoking. Pediatr Res 2001;49:558-65.

14 Kraus HF, Campbell GA, Fowler MW, et al. Maternal nicotine administration and fetal brainstem damage: a rat model with implication for sudden infant death syndrome. Am J Obstet Gynecol 1981;140:743-6.

15 Suzuki K, Minei $\sqcup$, Johnson EE. Effect of nicotine upon uterine blood flow in the pregnant Rhesus monkey. Am J Obstet Gynecol 1980;136:9-13.

16 Longo LD. The biological effects of carbon monoxide on the pregnant woman, fetus and newborn infant. Am J Obstet Gynecol 1977;129:69-103.

17 Bureau MA, Shapcott D, Berthiaume Y, et al. Maternal cigarette smoking and fetal oxygen transport: a study of P50, 2,3-diphosphoglycerate, total haemoglobin, hematocrit and type $\mathrm{F}$ in fetal blood. Pediatrics 1983;72:22-6.

18 Longo LW. Carbon dioxide: effects on oxygenation of the fetus in utero. Science 1976;194:522-4.

19 Zahalka EA, Seidler FJ, Lappi SE, et al. Deficits in development of central cholinergic pathways caused by fetal nicotine exposure: differential effects on choline acetyltransferase activity and $\left({ }^{3} \mathrm{H}\right)$ Hemicholinium-3 binding. Neurotoxicol Teratol 1992;14:375-82.

20 McFarland BJ, Seidler FJ, Slotkin TA. Inhibition of DNA synthesis in neonatal rat brains regions caused by acute nicotine exposure. Dev Brain Res 1991;58:223-9.

21 Seidler FJ, Levin ED, Lappi SE, et al. Fetal nicotine exposure ablates the ability of postnatal nicotine challenge to release norepinephrine from rat brain regions. Dev Brain Res 1992;69:288-91.

22 Slotkin TA, Lappi SE, Seidler FJ. Impact of fetal nicotine exposure on development of rat brain regions: critical sensitive periods or effects of withdrawal? Brain Res Bull 1993;31:3119-28.

23 Kinney HC, O'Donnell TJ, Kriger P, et al. Early developmental changes in $\left({ }^{3} \mathrm{H}\right)$ nicotine binding in human brain stem. Neuroscience 1993;55: $1127-38$

24 Milerad J, Larsson $\mathrm{H}$, Lin J, et al. Nicotine attenuates the ventilatory response to hypoxia in the developing brain. Pediatr Res 1995;37:652-60. 